\title{
Māori-medium Education: Current Issues and Challenges
}

\author{
Stephen May and Richard Hill \\ School of Education, University of Waikato, Hamilton, New Zealand
}

This paper summarises the key issues and challenges that have emerged from a recent major report by the authors on Māori-medium education in Aotearoa/New Zealand. The discussion is situated within a wider international analysis of bilingual/immersion programmes, including heritage language programmes for indigenous peoples. Key issues explored in the paper include the negotiation of, and occasional tension between, the wider goals of indigenous Mãori language revitalisation and the successful achievement of bilingualism and biliteracy in Māori-medium educational contexts. Issues to do with current pedagogy, staffing and resourcing of Māori-medium programmes are also examined. The paper concludes with suggestions for the ongoing development and extension of Mãorimedium education.

Keywords: Māori-medium education, heritage language programmes, immersion education, biliteracy, academic achievement

\section{Introduction}

Before discussing the latest developments in Māori-medium education in Aotearoa/New Zealand, three key areas of clarification are required. The first is that Aotearoa/New Zealand is one of the only national contexts that specifically distinguishes between bilingual and immersion education. Elsewhere, immersion education is regarded as one form of bilingual education. However, in Aotearoa/New Zealand, the two forms are consistently juxtaposed. This distinction is instantiated by the recognition, and associated funding, of four levels of immersion: Level 1, 81-100\%; Level 2, 51-80\%; Level 3, 31-50\%; Level 4, 12-30\%.

Immersion education is associated exclusively in the New Zealand context with Level 1 immersion and these programmes are, in turn, most often identified directly with the separate, whole-school programmes that have come to represent the Māori-medium movement - Te Kōhanga Reo (preschool), Kura Kaupapa Māori (elementary) and wharekura (secondary) Māorimedium programmes. Bilingual education is equated with lower levels of immersion (Levels 2-4), and these, in turn, are more often associated with a growing number of bilingual units within 'mainstream' (English-medium) schools. ${ }^{1}$

This distinction was solidified in the early years of the Māori-medium education movement, which began with the establishment of the first Kōhanga Reo in 1982. The kaupapa (philosophy) of Kōhanga and, subsequently, Kura Kaupapa Māori and wharekura Māori-medium schools, was predicated upon the central principle of 'He kōrero Māori' (speaking in Māori), ${ }^{2}$ and thus also 
the notion of 'full immersion' (Level 1: 81-100\%). The centrality of full immersion was, itself, a product of the widespread concern among Māori over the exponential loss of te reo Māori (the Māori language) that had followed the rapid urbanisation and subsequent dispersion of Māori after the Second World War. Indeed, as a result of a major sociolinguistic survey, it had been predicted in the 1970s that, unless the pattern of language shift and loss was attenuated, eventual language death would almost certainly occur (Benton, 1979; see also May, this issue). Promoting an educational environment where only Māori was spoken was thus seen as the best means by which to ensure the survival of, and an ongoing use for, te reo Māori. These views were also influenced at the time by the predominance in second language teaching circles of natural approaches to language learning, exemplified by the arguments of Krashen and Terrell's Natural Approach (see Richards \& Rodgers, 1986).

Moreover, prior to the emergence of the Māori-medium movement, the only other form of bilingual education available to Māori had been a limited number of transitional bilingual programmes, established in the 1970s, among the few isolated rural areas in the country that still remained predominantly Māori-speaking. As with most transitional bilingual programmes, however, while Māori was used as an instructional language, the main aim in the majority of these programmes was to shift the students towards greater use of English, rather than the retention of Māori itself (Benton, 1981). Consequently, for advocates of Māori-medium education, 'bilingual education' came to be associated, even elided, with subtractive models of bilingual education; hence the subsequent, and ongoing, juxtaposition with 'immersion education', which also presupposes an additive bilingual education approach. ${ }^{3}$

A second key point of clarification relates to the aims of the Māori-medium education movement. Up until recently, these aims have been framed from within the movement itself almost exclusively in terms of the role of education in revitalising te reo Māori - of achieving what Paulston has called 'language reversal': a process by which 'one of the languages of a state begins to move back into more prominent use' (Paulston, 1993: 281; see May, 2004 for an extended discussion). Not surprisingly perhaps, academic commentary on Māori-medium education, both nationally and internationally, has likewise focused almost exclusively to date on the significant successes that it has achieved in relation to this wider language revitalisation aim. Māori-medium education is regularly cited in the international literature, for example, as an exemplary school intervention that has successfully addressed, and redressed, the language shift and loss of an indigenous language (see, for example, Baker, 2001; Baker \& Prys Jones, 1998; May, 1999, 2004). Moreover, other indigenous language education programmes, such as those in Hawaii for example, have often looked to Mãori-medium education as a model of good practice in guiding the development of their own programmes and pedagogy (see Wilson, 1999).

And yet, despite the significance of these wider achievements (or, perhaps, to some extent, because of them), there remains an ongoing dearth of information on the factors that contribute specifically to the educational effectiveness of particular Māori-medium programmes, and the related academic outcomes of their students. Indeed, Cath Rau (2003: 2) comments 
that 'to date, there is little comprehensive information available to describe the achievement of students being instructed in the Māori language, especially in their formative years' (although, see Rau, this issue for the beginnings of just such an analysis). More extensive research and assessment of such programmes is thus urgently needed, particularly with respect to those conditions that promote the successful achievement of biliteracy, and thus educational achievement, among students in Māori-medium education (May et al., 2004). This is an area of focus that is only just now beginning to emerge in both the research on, and practice within, Māori-medium education itself (see also Rau, this issue). ${ }^{4}$

A third point of clarification relates closely to the other two. A key feature of any bilingual programme is the relationship between the students' language(s) and those of the programme. In particular, is the language of instruction the students' L1 or L2? Do all the students have the same language base (L1 or L2), or is the student language base mixed (a combination of both L1 and L2 speakers)? When these questions are asked, it immediately becomes apparent that most students currently in Māori-medium education are actually L1 speakers of English and L2 speakers of Māori as, indeed, are many of the teachers, as the latter are the generation that experienced personally the generational loss of the language. And yet, the L2 base of the students in Māori-medium education, and its implications for teaching and learning, is another key characteristic that has hardly been commented upon until recently, in either research on, or evaluation of, Māori-medium education.

This lacuna can be explained, at least to some extent, by a related ambiguity in much of the international research literature on bilingual/immersion programmes - particularly, with respect to the usual distinction employed between 'maintenance' and 'enrichment' bilingual education models. Both maintenance and enrichment approaches are recognised as additive bilingual education approaches that aim to achieve bilingualism and biliteracy for their students by the end of the programme and which aim also to contribute to the wider maintenance of the minority language(s) concerned in the wider community (see Baker, 2001; Hornberger, 1991).

The principal point of difference between maintenance and enrichment programmes appears to be the language base of the students in the programme. Maintenance models of bilingual education are most often associated with minority L1 speakers who are already fluent in their L1, to age-appropriate levels. Additive bilingual programmes for L1 Catalan and Welsh speakers, French-speaking Canadians, and L1 Spanish speakers in the USA might be said to constitute examples of maintenance bilingual programmes. Enrichment models, a term first coined by Fishman (1976), are most often associated with relatively privileged majority language L2 speakers being taught through a minority, or target, language. French immersion programmes in Canada, which cater predominantly for middle-class L1 English speakers, are perhaps the most often cited example here. Welshmedium schools, which also include many middle-class L1 English speakers, are another example (see May, 2000). Elite bilingual programmes such as the European Schools movement are also widely regarded as enrichment 
programmes (Skutnabb-Kangas, 1981; Valdes \& Figueroa, 1994). Given the nature of their constituency, in enrichment programmes the primary focus will be (and will need to be) on developing the L2 target minority language skills of these students, rather than maintaining an already existing age-appropriate language base in the L1, as in maintenance bilingual programmes.

The maintenance/enrichment distinction is a useful form of shorthand in the wider research literature, but it does not apply so easily to heritage language programmes - those programmes, such as Māori-medium education, which are most commonly associated with wider indigenous language revitalisation efforts (see Hinton \& Hale, 2001; May, 1999; May \& Aikman, 2003 for further discussion). Some of these indigenous language programmes are aimed at students who still speak the indigenous language as an L1 (e.g. Navajo; Hualapai in the USA; Inuit in Nunavut, Canada; Sámi in Finnmark, Norway) and may therefore be regarded as L1 maintenance bilingual programmes. But many also cater for students with a mix of L1/L2 speakers of the language (Māori, Hawaiian), and some have only L2 speakers (or, rather, learners) of the language (e.g. the Master/Apprentice programme developed for the now largely moribund indigenous languages of California; see Hinton \& Hale, 2001).

And yet, where heritage language programmes are discussed in the wider research literature, they tend to be described simply as an example of maintenance bilingualism, with the allied presumption that the majority of their students are L1 speakers of the indigenous language (see, for example, Baker, 2001). Given the clear continuum between maintenance and enrichment models, this description can be defended. Indigenous language programmes are, after all, most often based on additive bilingualism, with instruction in the indigenous language a central feature of these programmes. Moreover, there clearly are heritage language programmes that still comprise a majority of L1 speakers. However, even in indigenous language programmes that have traditionally drawn primarily from L1 speakers, more L2 speakers are increasingly present. For example, McCarty (2003) notes that in the Navajo heritage language programme at Rough Rock in Arizona - one of the strongest and longest established in the USA - only 50\% of Navajo now speak their own language and their numbers are declining each year.

The increasing presence of L2 speakers in heritage or indigenous language programmes is the ongoing consequence of already well established processes of language shift or loss for such languages, such as those experienced by Māori (see above; see also May, this issue). Given this, it is crucial that the wider research literature begins to address more clearly the specific consequences of the increase in L2 speakers in many heritage language programmes. In particular, we need to distinguish, and if necessary differentiate between, the specific language and learning needs of L1 and L2 speakers or learners of the minority language within these programmes. This can be accomplished in ways that will further enhance the developmental and educational outcomes of all the students involved, but only if these issues are directly addressed. At present, the increasing presence of L2 speakers continues to be either ignored, or subsumed within the L1 group, even though their educational circumstances and learning needs may differ. Baker's (2001) 
typology of heritage language education, for example, does not distinguish between these groups or their different needs and this is typical of the literature more generally. Much the same can be said for the research literature - at least until recently - on Māori-medium education, which has not addressed in sufficient depth the particular characteristics and demands of working in a predominantly L2 learning and teaching context (see also, Rau, this issue).

Bearing these three particular characteristics in mind, and with a specific focus on how best to achieve bilingualism and biliteracy for students, we will now provide a necessarily selective summary of recent research on Māorimedium education in Aotearoa/New Zealand over the last decade or so, drawing from our recent major report in this area (see May et al., 2004: Chapter 8 for an extended discussion). In so doing, we will also attempt to extrapolate key indicators of good practice for such programmes.

\section{Research on Māori-medium Programmes}

The relative paucity of discussions of Māori-medium education with specific reference to how best to foster biliteracy, and related academic outcomes for students, has already been noted. More extensive research and assessment of Māori-medium programmes is thus urgently needed, particularly with regard to these questions. Such research might assess effectiveness and student achievement, but it might also examine existing pedagogy and practice - highlighting good practices, but also where pedagogy and practice can be further improved and/or extended. Without such research information, it is very difficult to build upon the existing strengths of these programmes. Nonetheless, the beginnings of just such a consistent research basis are now beginning to emerge. The areas encompassed by this research include evaluations of Māori-medium programmes and the learning of the students who are involved in the programmes, teacher effectiveness in such programmes, and assessment processes and tools in Māori-medium contexts.

\section{Jacques (1991)}

One of the earliest evaluations of Māori bilingual/immersion programmes in Aotearoa/New Zealand was an evaluative study conducted by Jacques (1991) into the effectiveness of six South Island bilingual classroom-based programmes within mainstream (English-medium) primary schools. This study identified both the strengths and weaknesses of these particular programmes, within the educational context of home, school and community. It focused on:

(1) identifying the rationales for the establishment of the Māori bilingual units;

(2) identifying structures in place within the school to promote the programmes;

(3) describing the operations of bilingual classrooms including: availability of resources; teacher training and teaching practices; the roles and functions 
of the kaiarahi reo (language teaching assistants); and the incorporation of Māori language and culture into the curriculum;

(4) assessing the outcomes of the bilingual programmes, including: the students' affective development and development of English language skills; the retention of Māori language skills acquired at Kōhanga Reo; and the impact of the programmes on the school and wider community; and

(5) making recommendations for future programme development.

The research methodology consisted of quantitative and qualitative methods involving documentary evidence, interviews, classroom observations and surveys over an 18-month period from 1989 to 1990. The research participants included staff members, whānau (extended families), staff from kōhanga reo and the local community.

Jacques found that the programmes were very successful in terms of: the promotion of the students' self-esteem, self confidence and cultural identity; the provision of culturally sensitive and safe environments; the inclusion of families; and the development of the students' English language abilities. There were a number of factors, however, which militated against the promotion of te reo Māori and cultural maintenance goals. These included the following:

(1) the ongoing dominance of English as the language of instruction;

(2) the inadequacy of preservice and in-service training for associate teachers and kaiarahi reo with respect to teaching in bilingual contexts;

(3) the lack of adequate Māori language teaching resources for use in instruction;

(4) the lack of clear programme rationales;

(5) the lack of a clearly defined client-group (a wide range of students with differing fluency in te reo Māori were grouped together in classes);

(6) few effective support services;

(7) an absence of provision for the continuation of bilingual programming beyond primary school level;

(8) absence of local planning/advisory groups to assist in the steering of the programmes;

(9) resistance among some staff and community to the programmes;

(10) little promotion of kaupapa Māori practices in the wider school structures; and

(11) a widespread feeling among whānau whose children went to Kōhanga reo that their needs would be better met in a separate Māori language school, such as a kura kaupapa Māori, than in a bilingual unit within a mainstream school.

Māori language proficiency was not measured in the study. There were several reasons for this, one being that there were no measures at that time devised to assess the language (see also below), and another being that the researcher was not herself a fluent speaker of Māori. Instead, an impressionistic assessment was made of the students' fluency in Māori. The lack of data in such an important area and the researcher's inability to speak te reo Māori 
are thus a fundamental weakness of this research. This same feature - failing to assess adequately the students' knowledge of te reo Māori - is also a weakness of the Educational Review Office (ERO) evaluation of Kura Kaupapa Māori discussed below (see ERO, 2002) and points to a wider concern about the ongoing inability of Aotearoa/New Zealand research, and researchers, to address such an important consideration.

Nevertheless, in terms of what evidence Jacques does present regarding fluency in te reo Māori, she reports that the students displayed their use of te reo Māori on only a limited number of occasions, such as when reciting karakia (prayers) and during mihi (greetings), and when they took part in Māori language musical activities. One can infer from this that te reo Māori use was thus limited to organisational, rather than instructional language contexts. Likewise, in terms of listening comprehension, she observes that the students 'seemed to comprehend the Māori language speech of teachers and kaiarahi reo, and would for example, sit down, or go outside when asked, [but] they showed little age appropriate proficiency in either oral or literacyrelated tasks' (Jacques, 1991: 296; our emphasis). ${ }^{5}$

In terms of the students' English language skills, Jacques' research utilised the Progressive Achievement Test (PAT) to measure the students' reading comprehension, reading vocabulary and listening comprehension across two of the schools in the research study. In total, 239 Year 4-6 students were tested. Of these, one quarter of the students were enrolled in a bilingual class (using around $10 \%$ of te reo Māori, the target language) and the remainder were enrolled in mainstream English-only classes. The results indicated that although eight of the comparisons employed favoured the bilingual students, there was no significant difference between these students and those in English-medium. However, Jacques does point out that being enrolled in a bilingual class was clearly not a disadvantage for these students in their English language acquisition when compared with those in mainstream English-medium classes.

In her conclusions, Jacques provides an important caveat regarding the results. Although the evidence from her results ostensibly matches those found in studies of many overseas bilingual programmes, all the bilingual programmes that she examined had a significantly lower ratio than the $50 \%$ level of target language instruction ${ }^{6}$ - the minimum ratio considered to be characteristic of authentic bilingual programmes in the wider research literature (see, for example, Baker, 2001; Lindholm-Leary, 2001; May et al., 2004). Consequently, the data gathered cannot be directly compared with such programmes. It is also highly likely that the comparable performance of bilingual students in English language skills was the result of other factors such as cultural support - rather than linguistic factors.

\section{Hollings, Jeffries and McArdell (1992)}

Issues of Māori language assessment are addressed directly by a subsequent study by Hollings et al. (1992). In their study of 47 Māori-medium programmes, and via questionnaires and cluster interviews with 73 teachers in these programmes, these authors focused upon: 
(1) Māori language assessment;

(2) variables affecting Māori language;

(3) teachers' knowledge of assessment; and

(4) how assessment procedures are used in other situations (total immersion).

Results from the questionnaire found that teachers were using a wide variety of methods to assess Māori language development - generally, methods commonly found in mainstream (English-medium) schools, such as running records and six year net. However, incidental observation was the method most often used because of a lack of appropriate benchmarked assessment tools for te reo Māori at that time. Not surprisingly, the majority of teachers also felt that the available assessment procedures were not satisfactory.

Results from cluster meetings found that, while various forms of language assessment were regularly implemented in these programmes, few teachers demonstrated a sufficient understanding of their efficacy for L2 learners, or their appropriateness to L2 contexts - a crucial omission, given that, as discussed above, Māori is an L2 for most students in these programmes. It was also found that there was not much coordination in the recording of assessment. In fact, many teachers indicated that they based their decisions on a 'feeling' about the students' progress as they worked with them.

On the basis of these findings, Hollings et al. concluded that while most classroom assessment was at that stage still largely anecdotal and intuitive, this was primarily because of a lack of appropriate language assessment resources and related training in them. Certainly, teachers in the programmes were anxious to get further guidance about assessment practices. Accordingly, the study's principal recommendation was to improve the resource materials base in Māori language for schools, including Māori versions of the major language and literacy assessment tools available to mainstream Englishmedium schools (see also, Rau, this issue). Following from this, the authors argued that better coordination and sharing of information about language assessment among teachers in Māori-medium contexts should occur.

\section{Educational Review Office $(2000,2002)$}

The 1990s saw the subsequent development of key Māori language assessment tools for junior primary levels - particularly Ngā Kete Kōrero and Aromatawai Urunga-ā-Kura. ${ }^{7}$ However, a recent unpublished Educational Review Office (ERO) ${ }^{8}$ Report of literacy practices in Kura Kaupapa Māori (ERO, 2000) highlighted ongoing issues of concern about language assessment, as well as raising wider concerns about the development of academic literacy in te reo Māori.

With respect to curriculum management and planning, for example, the 2000 ERO Report concludes that there was not always sufficient evidence of planning to guide teachers with programme implementation, particularly in written and oral language in te reo Māori. Oral language programmes, for example, were not always well planned and tended to occur only incidentally. Those teachers who did plan for the teaching of reading, writing and oral 
language in te reo Māori tended to plan only basic sessions of instruction referenced to the curriculum documents.

Feedback from the teachers in these programmes also consistently highlighted the following ongoing concerns:

(1) The inadequacy of current preservice and in-service teacher training in literacy development in Māori-medium contexts, particularly biliteracy development, and second language acquisition more broadly.

(2) Neither the Māori nor the English curriculum documents were seen as adequately supporting the teaching of reading, writing and oral language in Māori immersion settings.

(3) An ongoing lack of sufficient Māori language benchmark assessment resources, particularly at more senior primary levels, and a related lack of training in their use. Those assessments that were available - particularly Ngā Kete Kōrero and Aromatawai Urunga-ā-Kura - were valued highly, however.

(4) An ongoing lack of adequate and appropriate teaching and learning resources.

An even more recent summary of the ERO Report's findings was published in 2002. The information from the 2002 ERO Report also incorporated the findings of the most recent reviews of 52 Kura Kaupapa Māori (KKM) with Level 1 (above 80\%) immersion levels in te reo Māori (ERO, 2002). As with its predecessor, the 2002 ERO Report continues to highlight the significant constraints experienced by KKM in terms of teaching, evaluating, programmes, planning and management. Surprisingly, however, the Report does not focus specifically on the quality of Māori language instruction or on the extent to which students were achieving fluency in te reo Māori. Only 16 of the $52 \mathrm{KKM}$ that were reviewed received specific comment regarding their te reo Māori programmes, of which ERO found that 12 had demonstrated good quality language programmes.

The Report did comment on the instructional methods teachers used to teach te reo Māori and found that at $23 \mathrm{KKM}$ the methods were appropriate and likely to lead to competency in both te reo Māori and English, while at seven KKM the teaching methods were less appropriate. However, the basis of this assessment is not stated, nor does the Report indicate the types of language competencies the reviewers focused upon - oral fluency, reading comprehension, etc. Given the centrality of bilingualism and biliteracy to the educational aims and practices of these Māori-medium schools, the analysis and findings of this ERO Report are disappointingly light on these crucial details.

There were a high number of other areas of instruction, assessment and governance that ERO deemed to be of concern in around $50 \%$ of the Kura Kaupapa Māori studied. These areas included curriculum planning, curriculum delivery, student assessment, meeting individual needs, learning environments, and administration and governance, the supply of staff and personnel, and teaching resources. The last two are largely beyond the control 
of the school, however, and are long-standing concerns in Aotearoa/New Zealand (see May et al., 2004 for further discussion).

The Report identified the greatest strengths of the KKM programmes as the use of cooperative learning techniques in instruction, effective learning environments, safe environments and relationships with the community. There are, however, some ambiguities in these areas as well. For example, the Report (ERO, 2002: 6-7) finds that most KKM have a good focus on providing an effective learning environment (62\%). This statement does not match the statistics stated elsewhere in the Report, however. In fact, earlier in the Report, only $54 \%$ of kura were said to have adequate systems for identifying learning needs, 56\% lacked effective mechanisms for assessing the progress and needs of the students, and curriculum delivery was effective in only $48 \%$ of the schools.

The available evidence from the 2002 ERO Report would thus suggest some ongoing concerns about the further development of effective learning environments in Māori-medium contexts. That said, the specific experience and/or expertise of the reviewers in bilingual, second language and/or Māorimedium education, or the specific criteria underlying their assessments of the bilingual programmes, are never made clear. Thus, the validity and reliability of their conclusions cannot be accurately gauged.

\section{National Education Monitoring Project (NEMP)}

The National Education Monitoring Project (NEMP) has the task of assessing and reporting on the achievement of New Zealand primary school students in all the subjects of the school curriculum. The main purpose is to provide detailed information about what students can do. Two recent Reports have focused on the comparative achievements of Year 8 Māori students involved in Level 1 immersion Māori-medium education, or within mainstream (English-medium) education.

In 2000, NEMP focused on assessing speaking and reading skills (NEARU, 2001), with 12 reading and speaking tasks being administered to these students. The tasks included reading comprehension, retelling a sequence that was viewed, completing a story and presenting an advertisement. Two tasks required all students to read Māori words or texts, although the task instructions were given in English for the Māori students in general education settings. The remaining 10 tasks were presented in Māori or English for the Māori-medium and English-medium students respectively. Administration of the tasks was either by videotape (nine tasks), one-to-one interview (one task) or station format (students work independently recording responses on paper; two tasks).

The results found that in three tasks the Māori-medium students performed at significantly higher levels than their English-medium peers. As one might expect, these included the two tasks that required all students to read Māori words or texts (pronouncing Māori words, oral reading in Māori). In five tasks, Māori students in both settings performed equally well (including presenting a news report, retelling a story from a picture book and completing a story). In four tasks, Māori students in general English- 
medium settings performed significantly higher (including reading comprehension and retelling a video story). The same Report also included research on Music skills and Technology skills for these students. From the total findings, the Report concludes that in $55 \%$ of the tasks, both groups performed similarly. In 14\% of tasks, the Māori immersion students performed better, and in $31 \%$ of the tasks the general English-medium students performed better (NEARU, 2001).

An earlier NEMP Report on science, art, graphs, tables and maps skills (NEARU, 2000) also found a broad comparability between Māori students in Māori-medium and English-medium settings, with both groups performing similarly in $70 \%$ of the tasks. In the remaining tasks, the English-medium students performed moderately better than the students in the Mãori-medium programmes (NEARU, 2000). While, in this case, the results were broadly similar, one clear advantage for the Māori-medium students was that they were able to perform as well as their English-medium peers, plus do so in their L2.

However, the 2001 NEMP Report also specifically warns about generalising from these results, for several reasons:

(1) The development and selection of some tasks may have advantaged the English-medium students, as mainstream teachers and researchers developed the majority of tasks.

(2) The earlier assessments were translations of English texts with which the Māori-medium students may not have been familiar, and which may have also included unfamiliar dialectal vocabulary.

(3) The activities in the Māori texts were often more complex than the English versions.

(4) The sample of immersion students unexpectedly lowered by 16 with the withdrawal of two classes.

(5) The students in the 1999 sample did not necessarily have stable Māori proficiency, as their te reo Māori abilities were not screened beforehand. Some may also have had only one or two years experience in Māorimedium contexts, thus also potentially disadvantaging them with respect to the assessment of grade appropriate material in te reo Māori. In order to redress this, the second sample in 2000 included only those students with at least 5 years in Māori-medium education.

(6) There are significant educational issues regarding the comparability of the English-medium and Māori-medium groups, given that Māori-medium education lacks resources and qualified teachers, something that Māori students in general English-medium schools would not experience. Rau (2003) and Rau et al. (2001) also specifically warn against the practice of comparing Māori with non-Māori and the use of non-Māori benchmarks to gauge Māori progress (see also below).

\section{Rau (2003)}

Rau (2003) has examined and compared the Māori-literacy skills of groups of students involved in Level 1 Māori-medium programmes over two periods, 1995 and 2002-2003 (see Rau, this issue for further discussion). The purposes 
of this assessment were to observe the literacy achievement of students in te reo Māori after at least one year of instruction in a high immersion context, to identify those experiencing difficulty, and to provide information about the classroom programmes. This, according to Rau, is important because no other standardised assessments currently exist in Māori that provide such comprehensive literacy information for students in the first three years of schooling.

Rau used a set of Māori-developed literacy assessments including those which tested letter identification (Te Taūtu), concepts about print (Ngā Tikanga o Te Tuhi Kōrero), word recognition (Te Whakamātautau kupu), writing vocabulary (Te Tuhi Kupu), hearing and recording the sounds in words (Whakarongo, Tuhia, Ngā Tangi o Roto i ngā Kupu) and text reading (Te Pānui Pukapuka). The participants were 97 students aged 6.0-7.0 years (the 1995 group), and 100 students aged 6.0-7.0 years (the 2002-2003 group). The results were as follows:

(1) Students in the 2002/3 sample scored consistently better than students in 1995 across five of the six tasks.

(2) Students in the older age bands scored consistently higher than the younger age band on all tasks for both the 1995 sample and the 2002/3 sample.

(3) Overall, there was little difference between the performance of boys and the performance of girls for both the 1995 and 2002/3 samples.

Rau argues that the different findings evident in 1995 and 2003 are attributable to a range of factors, including increased support for and resourcing of Māori-medium programmes, particularly since 1998. In particular, such resourcing has included:

(1) The development and promulgation of Ngā Kete Kōrero. This framework has provided much needed organisation of junior reading material in te reo Māori into increasing levels of difficulty, comparable to those in English-medium. Teachers potentially are able to make better matches between reading material and learner need/ability as a result.

(2) The increased quantity and improved quality of reading instructional material available in te reo Māori (although more is needed).

(3) The increased recognition and development of epistemology and pedagogy for Māori-medium contexts.

(4) The increased provision of Māori-medium-specific professional development in literacy for teachers, thus addressing the consistent need identified by teachers in Māori-medium programmes for such professional development.

(5) The ongoing commitment and dedication of Māori-medium teachers who continue to strive toward improving curriculum delivery and raising Māori achievement in the face of extreme demands, often overwhelming expectations, and limited resources. 
However, Rau also points out that the results may have been better still had it not been for a number of factors that have made the tasks of the Māorimedium teacher even more difficult. These include, in particular:

(1) the high number of 'linguistically challenging' curriculum documents in Māori that have been developed within a relatively short period;

(2) the high mobility of teachers;

(3) an increased demand for Māori-medium teachers due to a rapid increase in the number of schools offering Māori-medium programmes;

(4) increasing demands for professional development in Māori-mediumspecific literacy, which drains teacher supply; and

(5) the still piecemeal nature of teacher professional development provision.

\section{Berryman et al. (2002)}

In another recent research study, also pertaining to student achievement and assessment in Māori-medium education, Berryman et al. (2002) outline the development of a language assessment resource called Kia Puta ai te Reo. The study also discusses some preliminary findings from some Māori-medium programme trials of the resource.

Kia Puta ai te Reo consists of a combination of four programmes and assessment tools that are designed to assist students with different levels of language ability to improve their te reo skills in Māori-medium education settings.

The programmes are:

- Tukuna kia Rere. For students who need to strengthen and enrich their Māori language base. It is based on an English oral language programme called the 'One Hand Approach' and helps students build and link language by using a hierarchical model of word and meaning associations.

- Hopungia. For students who have learned to communicate in English but who need to develop Māori language skills in order to succeed in Māori language learning contexts. Hopungia consists of a range of interactive activities such as barrier games and collaborative stories, which are designed to broaden student understandings of Māori language and fluency.

- Mihi and Tata. These two programmes are designed to assist students who experience communication difficulties. Mihi is a programme designed to help parents of students with hearing difficulties. Tata works at developing vocabulary and the development of letter sound knowledge associated with the initial sounds of words.

Table 1 highlights the levels of the students' language ability in te reo Māori and the corresponding programmes that are designated to match that language ability level. Each type of programme caters for the needs of each particular group of students. Given their greater level of linguistic proficiency, however, Level One students use the standard Māori-medium assessments, 
Table 1 Kia Puta ai te Reo resources and corresponding language ability

\begin{tabular}{|l|l|c||}
\hline Level & Language ability of student & Corresponding programmes \\
\hline Level 4 & $\begin{array}{l}\text { Preschoolers who communicated } \\
\text { in mainly poor English or Māori } \\
\text { structures and vocabulary }\end{array}$ & Tata, Mihi \\
\hline Level 3 & $\begin{array}{l}\text { Preschoolers who communicated } \\
\text { only in English }\end{array}$ & Hopungia \\
\hline Level 2 & $\begin{array}{l}\text { Preschoolers who communicated } \\
\text { mainly in English but with some } \\
\text { Māori }\end{array}$ & Tukuna kia rere \\
\hline Level 1 & $\begin{array}{l}\text { Preschoolers who communicated } \\
\text { mainly in Māori }\end{array}$ & $\begin{array}{l}\text { Standard Māori-medium } \\
\text { school assessments }\end{array}$ \\
\hline
\end{tabular}

such as Aromatawai Urunga-ā-Kura, which are designed to ensure their ongoing extension in te reo Māori.

The preliminary results of the use of these programmes in the classroom are also now available. The Tata programme (testing the naming of objects and the initial sounds of selected vocabulary) has been successfully trialled in three sites. At each site there were increases in student performance over the period for both tests. The Hopungia programme has been trialled successfully at two sites, one a Kura Kaupapa Māori and the other a bilingual unit within a mainstream school (wishing to increase its Māori immersion level from Level 3 to Level 2 - i.e. to at least 50\%). In terms of these results, the authors state:

the Hopungia programme was enjoyed by students and able to be implemented by tutors working within the classroom setting. Further, the Hopungia programme was able to increase individual oral language opportunities and improved student performance at each of these quite diverse sites. (Berryman et al., 2002: 14)

The Tukuna kia Rere programme is still being trialled. However, the authors conclude that the overall implementation of Kia Puta ai te Reo appears highly promising and argue that it is one means of overcoming the past and present practices of Māori having to implement assessment tools which have been developed by non-Māori, and without Māori ways of knowing and understanding being an integral part of it. Therefore, this set of programmes marks a change from this pattern, as it was developed with te reo Māori me ōna tikanga (Māori language and culture) as the central resource, 'from within the context of equitable power-sharing ....and from the child's own culture' (Berryman et al., 2002).

\section{Berryman and Glynn (2003)}

Berryman and Glynn (2003); see also Glynn et al., this issue) have also conducted a small-scale intervention study in one community primary school 
where Māori-medium students were experiencing difficulties in their English language skills after transferring to the local English-medium high school. In addressing this concern, Berryman and Glynn asked the following key questions:

(1) What impact does transition to English have on the lives of the students and their whānau?

(2) Are current transition practices to mainstream English-medium effective, or even adequate?

(3) How have students benefited from these types of practices?

(4) How can we do better? (Berryman \& Glynn, 2003: 10)

Berryman and Glynn observed that, to date, most teachers in Māorimedium contexts have implemented one of three options when attempting to prepare their students for (English-medium) secondary school. They would typically either:

(1) do nothing to interfere with the ongoing Māori-medium education and wait until the student enters the English-medium context before dealing with any issues that might arise following transition;

(2) teach English transition once students reach a specific age group; or

(3) teach English transition to all students within a specific class.

None of these options above, Berryman and Glynn argue, is optimal, as they do not take into consideration the identified level of language proficiency of the individual student. All the options assume, they say, that the students share the 'same level of preparedness' (Berryman \& Glynn, 2003: 9-10). To address these concerns, Berryman and Glynn (2003) developed and implemented a 10-week reading and writing transition programme in English for the students in this Māori-medium setting, in Term 4 of their final year, immediately prior to transferring to high school. Despite the relatively short time frame, the results appear to have been highly successful, with the preparedness of the students for academic instruction in English markedly increasing. Subsequently, this programme time has been extended, to further build on its effectiveness (see Glynn et al., this issue for further discussion).

\section{Extrapolating Indicators of Good Practice for Māori-medium Education}

In light of the research undertaken to date on Māori-medium education, and in relation to attested principles of good practice in the wider literature on bilingual/immersion education, ${ }^{9}$ this paper concludes with implications for the further development of Māori-medium education. For reasons of space, only two key issues will be highlighted here: levels of immersion, and addressing the L2 language base of the majority of students in Māori-medium education (see May et al., 2004 for further discussion). 


\section{Levels of immersion in Māori-medium education}

In relation to the wider literature on bilingual/immersion education, the four levels of immersion identified in the New Zealand context can be situated as follows. Level $1(81-100 \%)$ programmes equate with high-level immersion programmes, most notably 90/10 maintenance and immersion models. Level 2 (51-80\%) programmes equate with effective 'partial immersion' programmes, including 50/50 models. Level $3(31-50 \%)$ equates with ineffective partial immersion programmes, as $50 \%$ instruction in the target language is regarded as the minimum necessary to achieve eventual bilingualism and biliteracy for students in the programme. ${ }^{10}$ Level 4 (12-30\%) equates with the level of instruction most often found in foreign language teaching programmes.

This hierarchy of immersion is also reflected in associated funding arrangements for these levels, as Table 2 indicates. This budget differential provides additional resources for New Zealand schools on the basis of the added costs involved in staffing and resourcing bilingual/immersion programmes. Higher levels of immersion involve more cost, in terms of staffing, resources and wider infrastructural support, and therefore gain greater funding.

Given the particular history of Māori-medium education, and its symbiotic relationship with the Kōhanga Reo movement from which it emerged, Level 1 immersion programmes are most often (but not exclusively; see below) associated with Kura Kaupapa Māori. These schools have also been the ones most often associated with the success of Māori-medium education, both nationally and internationally.

As discussed at the outset of this paper, the widespread adoption of a fullimmersion approach among Māori-medium programmes emerged out of a specific commitment to additive bilingualism, an associated awareness of the limitations of transitional bilingual education, and a wider social and political commitment to reversing language shift and loss of te reo Māori. This history of Māori-medium education is consequently reflected in the predominance of students in full immersion Māori-medium programmes. In 2000, just over 11,000 Māori students were involved in Level 1 Māori immersion, while less than half this number of Māori students (5117) were involved in Level 2 or Level 3 (5480). Level 1 programmes accordingly are also predominantly

Table 2 New Zealand Ministry of Education Māori language factor funding allowances

\begin{tabular}{|l|l|c|c||}
\hline $\begin{array}{l}\text { Immersion } \\
\text { level }\end{array}$ & Programme delivery & $\begin{array}{l}\text { \$\$ per Māori } \\
\text { student 2002 }\end{array}$ & $\begin{array}{c}\text { \$\$ per Māori } \\
\text { student 2003 }\end{array}$ \\
\hline Level 1 & $81-100 \%$ immersion & 886.69 & 902.65 \\
\hline Level 2 & $51-80 \%$ immersion & 443.34 & 451.32 \\
\hline Level 3 & $30-50 \%$ immersion & 221.67 & 225.66 \\
\hline Level 4 & $\begin{array}{l}\text { Less than 30\% but at least } \\
\text { 3 hours per week }\end{array}$ & 53.81 & 54.78 \\
\hline
\end{tabular}

Source: Resource Division of the New Zealand Ministry of Education (2002) 
separate whole-school programmes, while Level 2-4 programmes are predominantly associated with bilingual units within mainstream schools. This is also an important issue of resourcing, as the teachers who are most committed to Māori language revitalisation and/or are the most fluent speakers have also tended to teach in Kura Kaupapa Māori contexts.

The international research literature on bilingual/immersion education clearly indicates that a high level of immersion is entirely appropriate for the wider goal of revitalising te reo Māori, and the more specific goal of fostering the highest levels of language proficiency possible among students in te reo Māori, ${ }^{11}$ if the school or programme have the appropriate staff and resources to accomplish this.

However, the international research literature also clearly highlights that effective additive bilingual programmes may also be partial immersion programmes, as long as the minimum level of instruction in the language is at least 50\% - equating to Level 2 Māori-immersion (see May et al., 2004 for further discussion). This has not been a view that has been widely held in Aotearoa/New Zealand up until now. Indeed, what seems to have transpired in Aotearoa/New Zealand is a widespread view that only full immersion programmes (Level 1) can be described as authentic additive bilingual programmes - hence, the regular distinction in Aotearoa/New Zealand still made between immersion and 'other bilingual' programmes. Consequently, all partial forms of immersion (Levels 2-4), including the burgeoning number of bilingual units within mainstream school contexts, have tended to be viewed far less favourably - often being simply equated or elided with subtractive and/or transitional programmes.

It is equally clear from the international research literature, however, that many partial immersion programmes are ineffective. These programmes are almost always those that have less than $50 \%$ instruction in the target language and/or do not teach the target language sufficiently as a language of instruction - that is, the equivalent of Level 3 and Level 4 Māori-immersion in the Aotearoa/New Zealand context. Consequently, the basis of differentiation among Māori-medium programmes needs urgently to be reconsidered. Rather than differentiating between Level 1 full immersion programmes and all other partial immersion programmes, as is currently the case, the differentiation should be clearly between programmes at Levels 1-2 and Levels 3-4. Thus, partial immersion programmes that exceed 50\% - that is, Level 2 programmes - should continue to be specifically fostered in Aotearoa/ New Zealand along with Level 1 full immersion programmes. Level 1 programmes that move to more equivalent levels of instruction in Māori and English over time (e.g. 90/10 to 50/50 over six years), as is common in bilingual programmes internationally, should also not be penalised financially. For example, if the minimum level of immersion in Māori is maintained above $80 \%$ for the first $2-3$ years, these programmes should still be regarded as Level 1 programmes.

Meanwhile Level 3 and Level 4 programmes should be encouraged to meet these higher immersion levels, if possible, perhaps within a specified period of time. If they cannot - and one might expect this to be the case for the majority of current Level 4 programmes, and at least some of the Level 3 programmes - 
these programmes should be redesignated as Māori language support programmes, rather than as bilingual or Māori-medium programmes, and funded under a different basis (see also below).

The redesignation of Level 3 and Level 4 programmes is particularly important for any meaningful ongoing national evaluation of Māori-medium programmes, as only Level 1 and Level 2 programmes are regarded as being comparable to effective additive bilingual education programmes elsewhere, as identified consistently by the research literature. Such redesignation would also avoid the confusion that has characterised the debates on the effectiveness of bilingual education in the USA, where the less effective results from programmes with less than $50 \%$ instruction - the majority of US programmes, in fact - were included alongside the significantly and consistently more effective results from maintenance and enrichment programmes with more than $50 \%$ instruction. Consequently, undifferentiated national results on the effectiveness of 'bilingual education' in the USA were inevitably diminished overall. This has allowed the anti-bilingual campaign in the USA to continue to fuel public misunderstandings about bilingualism and bilingual education, a development that has actually led subsequently to the disestablishment of many of the most effective bilingual programmes (see Crawford, 2000).

If the emphasis on the further development of Māori-medium education was to be eventually concentrated and/or consolidated at Levels 1-2, this would also address a related concern with the current proliferation of Māorimedium programmes across the sector, many of which are at levels of immersion that are not considered to be effective. In other words, the further development of Māori-medium education should concentrate on quality or depth, not coverage or breadth - consolidating focus and resources on those programmes that have been identified as the most effective in achieving bilingualism and biliteracy for their students. This would also make best use of the limited staffing and resources currently available to Māori-medium education (although the latter should be extended wherever possible). In all instances, however, schools, parents and the wider whānau would need to be advised accurately on the significant benefits of higher levels of immersion, not least because of the ongoing misconceptions among many that 'too much' concentration on the target language will detrimentally affect the acquisition of English (see also below). This requires, in turn, a wider educational campaign aimed at highlighting the benefits of bilingualism and bilingual education, and addressing the many myths and misconceptions still surrounding them.

This approach to the further consolidation of Māori-medium education concentrating support on programmes that exhibit clear indicators of good practice - also highlights the relevance and importance of school or programme profiling. That is, programmes could be evaluated or assessed in relation to the degree to which they have incorporated and/or are cognisant of key indicators of good practice in bilingual/immersion education. This would address another pressing current concern - that is, the ad hoc development of many bilingual units in mainstream schools, often with little knowledge of, or consistency in, appropriate pedagogical approaches, particularly with respect to teaching a target language such as te reo Māori as an L2 (see below). 
This is not to suggest in any way that such programmes have been developed in a deliberately cavalier fashion. Rather, their development has most often been as a result of whānau, community and/or school-based initiatives. However, as this paper makes clear, such initiatives may actually prove to be counterproductive if they are not carefully developed and resourced in relation to good practices identified in the wider research literature, and in relation to bilingual programmes that have been identified as effective.

Finally, consideration also needs to be given to the particular school context in which bilingual/immersion programmes are situated. As has already been indicated, the majority of Level 1 or full-immersion programmes in Aotearoa/ New Zealand are Kura Kaupapa Māori - that is, separate whole-school te reo Māori programmes. As Table 3 indicates, however, there are also a considerable number of other whole-school Māori-medium programmes, at varying different levels of immersion - 154 in total. In addition, there are 276 schools that have bilingual units, or classes, within them - again, with widely different levels of immersion.

Whole-school bilingual/immersion programmes have several advantages over other options, not least in their potential to create an overall additive environment that is more conducive to learning the target language and attaining high academic levels in their subjects. In contrast, bilingual/ immersion programmes within English-medium schools will experience a number of challenges not experienced by whole-school programmes. When the target language programme is situated within a context where the majority language dominates, any additive bilingual context fostered by the programme may be potentially undermined by a wider subtractive view of the target language, and of the programme itself. Consequently, it is crucial to establish an additive environment towards the target language, and the programme itself, throughout the whole school (Johnson \& Swain, 1997). In this regard, Met and Lorenz (1997) make the point that effective bilingual programmes also place high emphasis on integrating all the students within the total school programme. This is demonstrated in the New Zealand context by the success of such schools as Richmond Road Primary School (see May,

Table 3 Number of Kura Kaupapa Māori and other Māori-medium schools

\begin{tabular}{|l|c|}
\hline Number of schools & Year 2000 \\
\hline Kura Kaupapa Māori & 59 \\
\hline Other immersion schools & 16 \\
\hline Bilingual schools & 79 \\
\hline Schools with immersion classes & 104 \\
\hline Schools with bilingual classes & 172 \\
\hline Total & 430 \\
\hline
\end{tabular}

Source: New Zealand Ministry of Education (2002: 28). 
1994, 1995) and Finlayson Park Primary School (McCaffery \& Tuafuti, 1998, 2003; Tuafuti \& McCaffery, this issue).

Successful bilingual/immersion programmes are also those that enjoy a high amount of parental support and involvement. Indeed, bilingual programmes are often created because of parental pressure on educational authorities to establish such a programme. The initial establishment of Kōhanga, and subsequently Kura Kaupapa Māori, demonstrate this clearly, as do many other Māori-medium programmes. This is also a characteristic of overseas programmes - the initial Canadian French immersion programmes, for example, and indigenous language education programmes more broadly (Cloud et al., 2000; May, 1999).

\section{The L2 language base of Māori-medium education}

In Aotearoa/New Zealand, L1 maintenance models of bilingual education are uncommon. Some of the Pasifika bilingual programmes, particularly in Auckland, will include students already fluent in their L1 to age-appropriate levels, particularly, but not exclusively, if they are Samoan or Tongan speakers (see May; Tuafuti \& McCaffery, this issue). However, the vast majority of bilingual programmes - including those in Māori-medium education - are likely to have, at the very least, a mix of L1 and L2 students within them and, more likely, a predominance of L2 speakers. Add to this the fact that many teachers in Mãori-medium education are themselves L2 speakers, ${ }^{12}$ and the language base of Māori-medium education takes on even greater importance.

This is particularly relevant to the rapid expansion of Māori-medium programmes, particularly within mainstream (English-medium) school contexts, in recent years. As Jacques (1991) research highlighted early on, there is a high likelihood that many of these programmes are not teaching sufficiently through te reo Māori as the target language for the programmes to achieve bilingualism and biliteracy for their students, particularly those Level 3 and Level 4 programmes that fall below the 50\% immersion threshold.

Given the significant and ongoing dearth of fluent Māori-speaking teachers in Aotearoa/New Zealand, serious and urgent consideration needs to be given to developing preservice and in-service programmes that combine the specific development of Māori language proficiency with the specific requirements of teaching in bilingual/immersion contexts. Consistent use of other fluent speakers in the classroom should also be encouraged wherever possible, perhaps via the use of kaiarahi reo (language assistants). This team teaching approach is widely evident in good models of bilingual education elsewhere (Cloud et al., 2000; Lindholm-Leary, 2001), as well as in English second language education (Bourne, 2001). It would also be particularly useful where the teacher's language fluency is in need of further development, allowing the teacher, as well as the students, access to fluent models of te reo Māori. Again, however, it would be important to ensure that Māori was consistently used as an instructional language in the classroom.

The L2 base of many of the students in Māori-medium education also has another important implication - programmes need to account specifically for the widely recognised second language learning delay with respect to the 
acquisition of academic language proficiency in an L2 (see, for example, Corson, 2000; Cummins, 2000). In this respect, wider indicators of the most effective bilingual education programme types highlight that students need to remain in bilingual programmes for a minimum of 6 years, ideally 8 years. Shorter programmes do not allow for the full development of literacy in the target language (see, Ramírez, 1992; Thomas \& Collier, 2002) - particularly when it is an L2, as it will be for the majority of Māori-medium students.

The particular concern that this raises for Māori-medium education relates to the misplaced assumption among many parents and whānau that $2-3$ years of Kōhanga, where some conversational Māori has been acquired, is 'sufficient', and that students' English language learning needs are then best served by transferring to English-medium contexts. Similarly, many parents of primary level Māori-medium programmes withdraw their children after only 1-2 years for, one suspects, much the same reason - the (misplaced) assumption that 'too much' Māori may undermine English language proficiency. ${ }^{13}{ }^{1}$

Parental decisions such as these not only waste the already overstretched resources of Māori-medium education programmes, which have invested considerable time educating these children, but are, ironically, the least effective means of achieving parental aims. The students concerned will almost certainly have had insufficient time in Māori-medium contexts to have acquired literacy in te reo Māori to age-appropriate level, given that the second-language learning delay inevitably sees such students at lower than equivalent grade level in the L2 in the initial years of instruction, before then beginning to catch up. This feature was recognised by the NEMP studies discussed above, for example.

As such, these students will (possibly) have conversational competence in te reo Māori, but not academic language proficiency in it. The students will also therefore not be at a sufficient bilingual threshold to be able to transfer literacy skills effectively from one language to the other, the principal advantage of additive bilingual education. As Baker (2001: 210) asserts, 'classroom teaching transfers relatively easily between languages [but only] when such languages are sufficiently developed to cope with concepts, content and curriculum materials'.

In short, students who arrive in English-medium school contexts without a sufficient literacy basis in te reo Māori are highly likely to struggle with academic English and learning more generally. They will be having to start again in a new language-learning context and, given their prior involvement in Māori-medium education, will also be behind their chronologically aged peers in relation to age-related learning activities in English. English-medium schools may, in turn, view these students and their Māori-medium experience from a deficit perspective, a pattern that Flores et al. (1991) have identified in the US context, further contributing to the potential difficulties experienced by such students in English-medium contexts.

A similar, but more easily managed consideration has to do with the transition to English-medium secondary education for Māori-medium students. Again, this relates to the issue of academic language proficiency albeit, this time in English. The early predominant view of many Kura Kaupapa Māori was that total immersion in Māori could be pursued because 
many of the students were L1 English speakers anyway, because of the pervasiveness of English elsewhere, and because of the related assumption that students would 'naturally' acquire the English necessary for instruction in English-medium instruction. These views were also influenced at the time by the predominance in second language teaching circles of natural approaches to language learning, as discussed in the Introduction, which espoused language programmes that imitated as closely as possible the process of learning the first language as the best means of achieving bilingualism (Lindholm-Leary, 2001).

However, academic language proficiency in any language, even one's L1, never automatically occurs. The particular and additional complexities of classroom-based academic discourse - including its more decontextualised nature, its more complex grammar, and its subject specific vocabulary (see Cummins, 2000) - have to be specifically taught.

The recent research by Berryman and Glynn (2003; see also Glynn et al., this issue) is therefore extremely important in this regard. It highlights that students who move from a primary school Māori-medium context to a secondary school English-medium context, without any formal instruction in academic English, may also experience issues of transition to a different language context, and may be similarly constructed in deficit terms by their new schools. However, unlike those who leave Māori-medium contexts too early, these students have the considerable advantage of being able to transfer the literacy skills acquired in te reo Māori to the task of learning academic English. And, as Berryman and Glynn demonstrate, this process can also be managed relatively straightforwardly. However, it does require Māorimedium contexts to directly address academic English at some point prior to the end of their programme, something that many Māori-medium programmes remain reluctant to do. It is this ongoing pattern of resistance to the teaching of English in full-immersion Māori-medium contexts that has led Jim Cummins (2000: 194) to observe specifically of Māori-medium education:

The rationale is that the minority language (Māori) needs maximum reinforcement and transfer of academic skills to English will happen 'automatically' without formal instruction. Although there may be instances where this does happen, in my view, this assumption is seriously flawed. 'Automatic' transfer of academic skills across languages will not happen unless students are given opportunities to read and write extensively in English in addition to the minority language.

Cummins emphasises the importance of formal explicit instruction in order to teach specific aspects of academic registers in both languages and the utilisation of both languages to promote students' awareness of language and how it works (e.g. focusing on similarities and differences between the two languages). He proceeds to argue that if one of the two languages is ignored instructionally, with the expectation that it will 'take care of itself', students may experience significant gaps in their knowledge of, and access to, academic registers in that language, particularly in areas related to writing. Furthermore, if one language is completely excluded, students are given much less opportunity and encouragement to engage in the 'incipient contrastive 
linguistics' that Lambert (1984) reported was such a successful feature of French immersion programmes. This kind of enriching metalinguistic activity is much more likely to occur and exert positive effects if it is actively promoted by instruction.

There is far less consensus in the wider research literature on the best timing for, and method of, such instruction in English - although usually bilingual/ immersion programmes have introduced instruction in both languages by Year 4 (Baker, 2001). In contrast, many Level 1 Māori-medium programmes do not begin English language instruction until Year 4 or 5, and often then only for one or two hours each week, while others may leave it until as late as Year 7 and 8, as we saw in Berryman and Glynn's (2003) intervention study. Given the importance of biliteracy to the academic achievement of bilingual students, it would seem that an earlier introduction of academic English in Māorimedium Level 1 programmes might thus prove to be advantageous. However, this is where the wider aims of Māori language revitalisation and the need to 'ring-fence' Māori from English within the educational system may well run counter to the best educational interests of the students.

Finally, how effectively teachers understand and address the complex issues that attend teaching in an L2 as an instructional language, and the teaching of academic literacy in both an L1 and L2, are pivotal to the success or otherwise of bilingual/immersion programmes. Specifically, teaching in a bilingual programme requires specialist training in immersion pedagogy, curriculum, materials and resources, and L2 or target language assessment. This must include preservice and ongoing in-service in:

(1) bilingual theory and research;

(2) the bilingual programme model the school uses;

(3) second language acquisition and development;

(4) instructional strategies in second language development;

(5) bicultural, multicultural and educational equity training; and

(6) cooperative learning strategies. ${ }^{14}$

Not only do Māori-medium teachers need to be skilled practitioners, an important element is also their ability to reflect critically upon their instruction and the curriculum. According to Cloud et al., (2000), effective instruction occurs when teaching is modified in response to the results of formal and informal assessment of student progress, to feedback from students during activities, and to teachers' observations of the appropriateness of curriculum materials and activities. In order to be able to do this competently, particularly in an L2 minority language context, teachers must have a repertoire of appropriate and effective assessment techniques that they are able to use to obtain regular feedback about the effectiveness of their teaching and the learning of the students.

Research in Aotearoa/New Zealand - particularly Hollings et al . (1992) and ERO (2002) - suggests that this repertoire among Māori-medium teachers is still in need of further support and development. And yet, an integrated approach to preservice training and in-service professional development for Māori-medium education, along the lines suggested, is only just now 
beginning to be countenanced in Aotearoa/New Zealand, despite consistent advocacy by Māori-medium teachers for just such an approach, for well over 15 years.

\section{Conclusion}

This paper has discussed the key characteristics and trends currently evident in Māori-medium education, with particular reference to biliteracy and academic achievement. It has also attempted to situate these characteristics and trends within wider, attested, indicators of good practice in bilingual/immersion education worldwide.

In highlighting these issues, it has not been our intention to present here an overly negative picture of current issues facing Māori-medium education. Indeed, what Māori-medium education has managed to achieve over the last 20 years is quite remarkable, particularly given the generational loss of te reo Māori that preceded it. Rather, we wanted to highlight that these issues and concerns constitute, crucially, the next phase in its development. This, in turn, requires a closer, more consistent, examination of the specific pedagogical issues attendant upon Māori-medium education. In particular, issues surrounding levels of immersion and its predominantly L2 language base need to be seriously addressed, in order to ensure the achievement of biliteracy, and the best possible academic outcomes, for students.

Such emphases also provide an important basis for the development of effective bilingual/immersion education models for other language minority groups in Aotearoa/New Zealand, particularly for Pasifika students. However, the extent of the effort required to establish Māori-medium education to even this level, coupled with the New Zealand state's spectacular lack of interest in pursuing bilingual education for other groups, suggest that this latter possibility remains some way off.

\section{Correspondence}

Any correspondence should be directed to Professor Stephen May, School of Education, University of Waikato, Private Bag 3105, Hamilton, New Zealand (s.may@waikato.ac.nz).

\section{Notes}

1. That said, this demarcation is not quite as clear cut as it is sometimes made out to be; see the later discussion on levels of immersion.

2. For an extended discussion of the key principles underlying Kōhanga Reo and Kura Kaupapa Māori, see May (2004).

3. At the risk of rehearsing what is already widely known, subtractive educational approaches aim to move students from their minority L1 to a majority L2, most often, as soon as possible. In contrast, additive bilingual education approaches include those that teach in students' L1, if this language is different from the majority language - as, for example, with L1 Spanish-speakers in the USA - in order to promote eventual bilingualism and biliteracy. Additive bilingual education also includes those programmes that teach in a minority or target language that is an L2 for many students - as is the case for immersion educational approaches. This is because the specific aim of such programmes is to maintain the target language (thus ensuring bilingualism and biliteracy) in the face of a majority 
language that would otherwise swamp it - hence, the need to teach through the medium of the target language to 'ring fence' the language.

4. Interestingly, other forms of bilingual/immersion education in Aotearoa/New Zealand are much less prevalent, except for a few school-based bilingual programmes for Pasifika students (see May; Tuafuti \& McCaffery, this issue). However, the limited research available on Pasifika bilingual education has already focused explicitly on the issues of biliteracy and academic achievement in relation to these programmes (see May, 1994; McCaffery \& Tuafuti, 1998, 2003).

5. In light of her previous observations, Jacques' assessment here is highly likely to have been accurate. However, given the researcher's own lack of fluency in te reo Māori, and the related lack of an accurate and appropriate Māori language assessment measure, some caution still needs to attend this conclusion.

6. Although levels of immersion had not been formalised at that time, it is likely that all the bilingual programmes examined by Jacques would have equated with only Level 4 immersion (12-30\%) - a level of instruction not that dissimilar to foreign language teaching.

7. Ngā Kete Kōrero is a Māori language method of organising reading materials into various levels of reading difficulty that was developed in the mid-1990s, although this does not currently extend beyond beginning and early reading texts. Aromatawai-Urunga-ā-Kura (AKA) is a standardised assessment tool to assess literacy and numeracy at school entry in te reo Māori and has been available since 1997 (for further discussion of both forms of assessment, see Rau, this issue).

8. The Educational Review Office is responsible for auditing the organisational and educational effectiveness of all New Zealand schools (and preschools). It is broadly equivalent to OFSTED in Britain.

9. The latter, general research principles are discussed at length in May et al . (2004). However, given that these principles are widely known by those working within the bilingual/immersion field, they are not rehearsed again here, except by way of implication for the further development of Māori-medium programmes.

10. Level 3 programmes are highly likely to be operating at the lower percentage levels in terms of immersion - i.e. nearer the $30 \%$ mark than the $50 \%$. Those that operate at the $50 \%$ threshold would almost certainly opt for Level 2 immersion recognition.

11. The only proviso is that some form of specific academic English language instruction should occur before the end of the programme (see also below).

12. Of course, second language learners can also be fluent speakers and writers of the language. However, the second language base of teachers in Māori-medium education does nonetheless present a possible further challenge to address, as language fluency is a central prerequisite for successful bilingual programmes and a sine qua non for discussions of bilingual/immersion education in the wider literature. In particular, good models of the language are essential, particularly when the target language is an L2 for students, if students are to have modelled to them cognitively stimulating instruction (Lindholm-Leary, 2001).

13. These trends are supported by New Zealand Ministry of Education data. In 2000, for example, over $30 \%$ of Māori children were enrolled in Kōhanga Reo at the highest level of immersion, Level $1(81-100 \%)$, but only $7.5 \%$ of Māori children subsequently moved on to the same level of Māori immersion education at the primary school level. Out of the remaining three levels of Māori medium education, 3.5\% were involved in Level 2 (51-80\% immersion) and 3.7\% in Level 3 (31-50\% immersion). Level 4 immersion (12-30\%) was not addressed (New Zealand Ministry of Education, 2002).

14. For further discussion, see Cloud et al., 2000; Day \& Shapson, 1996; Met \& Lorenz, 1997; Skutnabb-Kangas \& García, 1995. 


\section{References}

Baker, C. (2001) Foundations of Bilingual Education and Bilingualism (3rd edn). Clevedon: Multilingual Matters.

Baker, C. and Prys Jones, S. (1998) Encyclopedia of Bilingualism and Bilingual Education. Clevedon: Multilingual Matters.

Benton, N. (1981) The Flight of the Amokura. Wellington: NZCER.

Benton, R. (1979) Who Speaks Māori in New Zealand. Wellington, New Zealand: New Zealand Council for Educational Research.

Berryman, M. and Glynn, T. (2003) Transition from Māori to English: A Community Approach. Wellington: NZCER.

Berryman, M., Walker, R., Reweti, M., O'Brian, K. and McDonald, S. (2002) Kia puta ai te reo: An essential foundation for literacy. Paper presented at the NZARE conference, Palmerston North, New Zealand.

Bourne, J. (2001) Doing 'what comes naturally': How discourses and routines of teachers' practice constrain opportunities for bilingual support in UK primary schools. Language and Education 15, 250-268.

Cloud, N., Genesee, F. and Hamayan, E. (2000) Dual Language Instruction: A Handbook for Enriched Education. Boston: Thomson Heine.

Corson, D. (2000) Language Diversity and Education. Mahwah, NJ: Lawrence Erlbaum.

Crawford, J. (2000) At War with Diversity. US Language Policy in an Age of Anxiety. Clevedon: Multilingual Matters.

Cummins, J. (2000) Language, Power and Pedagogy: Bilingual Children in the Crossfire. Clevedon: Multilingual Matters.

Day, E.M. and Shapson, S. (1996) Studies in Immersion Education. Clevedon: Multilingual Matters.

ERO (2000) Literacy Education in Kura Kaupapa Māori. Wellington: Education Review Office.

ERO (2002) The Performance of Kura Kaupapa Māori. Wellington: Education Review Office.

Fishman, J. (1976) Bilingual Education: An International Sociological Perspective. Rowley, MA: Newbury House.

Flores, B., Cousin, P. and Diaz, E. (1991) Transforming deficit myths about learning, language and culture. Language Arts 68, 369-377.

Hinton, L. and Hale, K. (2001) The Green Book of Language Revitalization in Practice. San Diego: Academic Press.

Hollings, M., Jeffries, R. and McArdell, P. (1992) Assessment in kura kaupapa Māori and Maori language immersion programmes: A report to the Ministry of Education. Wellington: Ministry of Education.

Hornberger, N. (1991) Extending enrichment bilingual education: Revisiting typologies and redirecting policy. In F. Coulmas (ed.) The Handbook of Sociolinguistics. Oxford: Blackwell.

Jacques, K. (1991) Community Contexts of Māori-English Bilingual Education: A Study of Six South Island Primary School Programmes. Christchurch: University of Canterbury.

Johnson, R. and Swain, M. (1997) Immersion Education. Cambridge: Cambridge Applied Linguistics.

Lambert, W. (1984) An overview of issues in immersion education. In Studies on Immersion Education. Sacramento: Office of Bilingual Bicultural Education, California State Department of Bilingual Bicultural Education, California State Department of Education.

Lindholm-Leary, K. (2001) Dual Language Education. Clevedon: Multilingual Matters.

May, S. (1994) Making Multicultural Education Work. Clevedon: Multilingual Matters.

May, S. (1995) Deconstructing traditional discourses of schooling: An example of school reform. Language and Education 9, 1-29.

May, S. (ed.) (1999) Indigenous Community-based Education. Clevedon: Multilingual Matters. 
May, S. (2000) Accommodating and resisting minority language policy: The case of Wales. International Journal of Bilingual Education and Bilingualism 3 (2), 101-128.

May, S. (2004) Medium of instruction policy in New Zealand. In J. Tollefson and A. Tsui (eds) Medium of Instruction Policies: Which agenda? Whose Agenda? (pp. 21-41). Mahwah, NJ:. Lawrence Erlbaum Associates.

May, S. and Aikman, S. (eds) (2003) Indigenous education: New possibilities, ongoing restraints. Special Issue. Comparative Education 39, 2.

May, S., Hill, R. and Tiakiwai, S. (2004) Bilingual/Immersion Education: Indicators of Good Practice: Final Report to the Ministry of Education. Wellington, New Zealand: Ministry of Education. On WWW at http://www.minedu.govt.nz/index.cfm?layout = document\&documentid $=9712 \& ;$ data $=1$. Accessed on 2/5/05.

McCaffery, J. and Tuafuti, F. (1998) The development of Pacific Islands bilingual education in Aotearoa/New Zealand. Many Voices 13, 11-16.

McCaffery, J. and Tuafuti, P. (2003) Children's bilingual language and literacy development in a Samoan-English bilingual unit. In R. Barnard and T. Glynn (eds) Case Studies in Bilingualism. Clevedon: Multilingual Matters.

McCarty, T. (2003) Revitalising indigenous languages in homogenizing times. Comparative Education 3 (2), 147-163.

Met, M. and Lorenz, E.B. (1997) Lessons from US immersion programs: Two decades of experience. In J. Cenoz (ed.) Beyond Bilingualism: Multilingualism and Multilingual Education. Clevedon: Multilingual Matters.

NEARU (2000) Assessment Results for Māori Students 1999: Science, Art, Graphs, Tables and Maps. Dunedin: National Educational Assessment Research Unit.

NEARU (2001) Assessment Results for Māori Students 2000: Music, Aspects of Technology, Reading and Speaking. Dunedin: National Educational Assessment Research Unit.

New Zealand Ministry of Education (2002) Nga haeata matauranga: Annual Report on Māori Education 2000/2001. Wellington: Ministry of Education, Group Māori.

Paulston, C. (1993) Language regenesis: A conceptual overview of language revival, revitilisation and reversal. Journal of Multilingual and Multicultural Development 14, $275-286$.

Ramírez, J. (1992) Executive summary. Bilingual Research Journal 16, 1-62.

Rau, C. (2003) A Snapshot of the Literacy Achievement of Year 2 Students in 80-100\% Māori Immersion Programmes in 1995 and 2002-2003 and the Impact of Teacher Professional Development on that Achievement. Wellington: Ministry of Education.

Rau, C., Whiu, I., Thomson, H., Glynn, T. and Milroy, W. (2001) He ara angitu. A Description of Success in Reading for Five-year Old Māori Medium Students. Wellington: Ministry of Education.

Richards, J. and Rodgers, T. (1986) Approaches and Methods in Language Teaching. New York: Cambridge University Press.

Skutnabb-Kangas, T. (1981) Bilingualism or Not: The Education of Minorities. Clevedon: Multilingual Matters.

Skutnabb-Kangas, T. and García O. (1995) Multilingualism for all: General principles. In T. Skutnabb-Kangas (ed.) Multilingualism for All (pp. 222-256). Lisse: Swets \& Zeitlinger, Amsterdam, Series European Studies on Multilingualism.

Thomas, W. and Collier, V. (2002) A National Study of School Effectiveness for Language Minority Students' Long-Term Academic Achievement. Santa Cruz: Center for Research on Education, Diversity and Excellence (CREDE).

Valdes, G. and Figueroa, R.A. (1994) Bilingualism and Testing: A Special Case of Bias. Norwood, NJ: Ablex.

Wilson, W. (1999) The sociopolitical context of establishing Hawaiian-medium education. In S. May (ed.) Indigenous Community-based Education (pp. 95-108). Clevedon: Multilingual Matters. 